\title{
Nahuas y Cherokees: tierra, lucha y reinvención. El proceso de individualización en el siglo XIX
}

Laura Machuca Gallegos (D) https://orcid.org/(0000-(00)2-(0179-3212

CIESAS-Peninsular, México

laurama@ciesas.edu.mx

María del Pilar Monroy, Nahuas y Cherokees: tierra, lucha y reinvención. El proceso de individualización en el siglo XIX, Guadalajara, Universidad de Guadalajara, 2018.

Aunque estemos en la época de la historia conectada, globalizada, digitalizada, etcétera, la comparación nunca estará de más. Marc Bloch (1999, p. 108) en su célebre artículo de 1930 sobre la comparación escribía que consistía en "buscar las similitudes y diferencias que existen entre series de fenómenos de naturaleza análoga que han sido tomados de diferentes medios sociales con el objeto de explicarlos”. Esto es precisamente lo que hace Pilar Monroy a lo largo de ocho capítulos. Como primera idea, el lector pensaría que nahuas y cherokees tuvieron más diferencias que similitudes, más de uno pensaría que ni siquiera son comparables. ¿Los civilizados indígenas de Mesoamérica qué podrían tener en común con los “apaches” del norte? Las apariencias engañan.

Como la misma Pilar Monroy lo subraya, el propósito de su trabajo es "entender cómo fue el proceso de individualización de las tierras comunales en dos grupos indígenas a lo largo del siglo XIX; los nahuas del sur de Jalisco, México, y los cherokees de Oklahoma, Estados Unidos” (p. 16). Las palabras clave que guían el trabajo son tierras comunales, individualización y religiosidad. Es decir, ante el proceso individualizador, los pueblos hicieron un frente común, cerraron filas e hicieron efectivamente comunidad, la cual se expresó en sus ceremonias religiosas, y aunque seguramente pasaron por un proceso de adaptación o de 
reinvención, fueron ampliamente socorridas. Entonces la política liberal decimonónica y su impacto en los pueblos indios, en el contexto de la formación del estado están en el centro del análisis. Aunque el objetivo de esta política era crear ciudadanos propietarios, lo logró, pero a medias, ya que el sustrato básico no desapareció: el pueblo, la comunidad.

El libro consta de tres partes, en la primera, la autora abarca el proceso de individualización, para lo cual se centra inicialmente en el antiguo orden corporativo, para después explicar el liberalismo y el proceso individualizador. En la segunda parte explica la individualización de las tierras comunales de los nahuas y las festividades religiosas como escape o "refugio" a esta situación. En la tercera parte se aboca a estudiar el mismo proceso, pero en la sociedad cherokee: somos testigos de la manera en que los "fullblood", es decir los legítimamente cherokees, revivieron sus antiguos mundos míticos. La autora se apoya en la etnohistoria, disciplina que da un especial valor al documento escrito y que resulta "una herramienta política y de memoria colectiva” (p. 33.) Con la lectura también nos damos cuenta del uso de material etnográfico y ampliamente de la historia oral.

Marc Bloch, en el mismo artículo ya mencionado, apuntaba los resultados que se pueden esperar del método comparativo y quisiera hacer alusión a algunos de ellos, para resaltar las contribuciones del libro que ahora se comenta:

A. "Capacidad para el establecimiento de similitudes y diferencias evolutivas y para buscar las causas de las mismas.” Como nos explica Monroy el orden comunal cherokee en Territorio Indio se basaba en tres aspectos: (I) tenencia comunal de las tierras, que eran distribuidas para ser laboradas por familias extensas; (II) la labor en la tierra se basaba en las relaciones matrilineales cherokees; y (III) preservación de la nación tribal. Con los nahuas la relación era muy parecida, salvo que con los nahuas el sistema de parentesco era virilocal y la comunidad era la que aglutinaba a sus integrantes. 
En Jalisco, y en general en México, el proceso individualizador empezó desde 1824 (incluso varios autores lo datan mucho antes) y fue un proceso largo; en cambio, en Estados Unidos inició después de la guerra civil, en 1866, y fue expedito. No obstante, la autora encuentra las siguientes convergencias:

1) La centralización y presencia del Estado implicó el aniquilamiento de sus bienes comunales, y el fomento de intereses privados.

2) Una política clara de extinción de las corporaciones, por la ley Lerdo de un lado y la ley Dawes por otro.

3) Una engañosa extensión de ciudadanía, que los sacaba del refugio corporativo.

4) La puesta en duda de la legitimidad de los antiguos títulos de propiedad y la certeza prometida en los títulos individuales.

B) Marc Bloch también escribe que la historia comparativa requiere de la "capacidad para explicar las supervivencias y para realizar la interpolación entre las curvas de evolución”. Es decir, la aparición de fenómenos iguales en lugares muy diferentes y lejanos unos de otros y a veces en tiempos distintos.

En el caso nahua, las cofradías se fueron debilitando hasta ya no contar con bienes inmuebles ni con tierras, pero mientras esto pasaba las campanas sonaban, las misas cantadas se redoblaban, los santos fueron más visitados, es decir, como dice la autora: "la recreación de un mundo comunitario a nivel religioso centrado en las fiestas a los santos empezaba a aumentar” (p. 193). Como ella afirma, la tradición se reinventó y sigue.

Lo mismo sucedió del lado cherokee: ser Cherokee implicaba "haber compartido el dolor de la migración forzada”, y aunque no hubieran llegado al Territorio Indio, debía mantener el lazo con su familia, “compartir los intereses comunes de la nación india aceptando las leyes y Secuencia. E-ISSN 2395-8464 
las regulaciones del gobierno tribal", y "no haber abandonado la nación cherokee por libre elección”. La autora muestra que hubo sujetos que buscaban en su descendencia lejana el lazo cherokee en aras de obtener tierras. En 1898 se publicó el Acta Curtis, que abolía todas las instituciones cherokees, anulaba la ciudanía cherokee e imponía la estadunidense. No resistieron pues no querían más violencia, no había otra alternativa y sobre todo porque pensaban que esa era la marcha de la historia (p. 345).

Sin embargo, buscaron sus raíces, conservaron el fuego sagrado y rescataron la representación del Gran Espíritu, dios central y supremo que creó todo el universo. En la recuperación de tradiciones jugó un papel importante el Bureau de Etnología Americana, aunque lo consideraban como algo estático, una falsa esperanza. Por otro lado, estaba el Rebird y los miembros de la Nighthawk Society que se volvieron etnógrafos de su propio grupo, al rescatar todas las prácticas ceremoniales y reforzar una historia común.

C) Por último Marc Bloch escribe que una buena historia comparada requiere "capacidad para sugerir investigaciones”.

Sin duda el trabajo de Pilar Monroy es una contribución importante que invita a seguir por su camino. De hecho, hubo otros autores que tuvieron similar idea casi al mismo tiempo, y por eso no alcanzaron a citarse. Ingrid de Jong y Antonio Escobar (2016) coordinaron un libro llamado Las poblaciones indígenas en la conformación de las naciones y los Estados en la América Latina decimonónica, y el ejercicio ahí desplegado fue precisamente el de hacer historia comparada.

Nahuas y Cherokes se presentó primero como tesis doctoral y obtuvo el reconocimiento como la mejor tesis de su generación. La autora, de origen colombiano y estudiando en una universidad mexicana, se planteó el reto de entender otra cultura diferente a la suya, y al estar Secuencia. E-ISSN 2395-8464 
en Jalisco escogió la Nahua, pero decidió ir más allá de las fronteras y planteó asimismo el caso Cherokee, aumentando así la complejidad en el análisis. Esta es una invitación a leerla y aprender las múltiples adaptaciones de "los grupos originarios” a los cambios que les tocó vivir.

\section{Referencias}

Bloch, M. (1999). Comparación. En E. Bloch (comp.), Historia e historiadores. [trad. F. J. González García]. Madrid: Akal.

De Jong, I. y Escobar, A. (coords. y eds.). (2016). Las poblaciones indígenas en la conformación de las naciones y los Estados en la América Latina decimonónica. México: El Colegio de México/El Colegio de Michoacán/CIESAS. 